\title{
Bone Marrow Collection
}

National Cancer Institute

\section{Source}

National Cancer Institute. Bone Marrow Collection. NCI Thesaurus. Code C112933.

Any process that harvests bone marrow for clinical or manufacturing purposes. 